\begin{tabular}{|c|l|}
\hline Title & Effect of Photoexcited Electron Dynamics on Photocatalytic Efficiency of Bismuth Tungstate \\
\hline Author(s) & A mano, Fumiaki; Y amakata, A kira; Nogami, Kohei; Osawa, Masatoshi; Ohtani, Bunsho \\
\hline Citation & $\begin{array}{l}\text { The Journal of Physical Chemistry C, 115(33), 16598-16605 } \\
\text { https://doi.org/L0.1021/jp2051257 }\end{array}$ \\
\hline Issue Date & 2011 \\
\hline Doc URL & http://hdl.handle.net/2115/48655 \\
\hline Type & article \\
\hline File Information & JPCC_Ohotani.pdf \\
\hline
\end{tabular}

Instructions for use 


\title{
Effect of Photoexcited Electron Dynamics on Photocatalytic Efficiency of Bismuth Tungstate
}

\author{
Fumiaki Amano, ${ }^{*+,+}$ Akira Yamakata, ${ }^{\S}$ Kohei Nogami, ${ }^{\ddagger}$ Masatoshi Osawa, ${ }^{\dagger}$ and Bunsho Ohtani ${ }^{+, \neq}$ \\ ${ }^{\dagger}$ Catalysis Research Center, Hokkaido University, Sapporo 001-0021, Japan \\ ${ }^{\ddagger}$ Graduate School of Environmental Science, Hokkaido University, Sapporo 060-0810, Japan \\ ${ }^{\S}$ Department of Engineering, Toyota Technological Institute, Nagoya 468-8511, Japan
}

Supporting Information

\begin{abstract}
Photoexcited carrier dynamics of bismuth tungstate $\left(\mathrm{Bi}_{2} \mathrm{WO}_{6}\right)$ photocatalysts was investigated by time-resolved infrared (IR) absorption spectroscopy. Monotonic absorption at the mid-IR region, which is attributable to absorption by photoexcited electrons, was monitored as a function of time delay from the microsecond to millisecond range after photoexcitation. $\mathrm{Bi}_{2} \mathrm{WO}_{6}$ particles with different crystalline content were prepared by hydrothermal reaction at several temperatures and used to elucidate the relation between density of photoexcited carriers and steady-

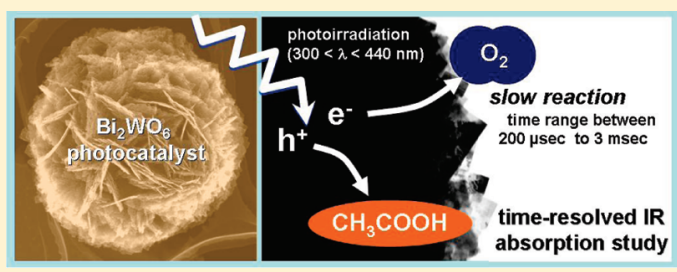
state photocatalytic efficiency. Photocatalytic efficiency was tested using two reactions: oxidative decomposition of acetic acid in an aqueous solution (reaction 1) and oxidative decomposition of acetaldehyde in air (reaction 2). Crystallization of $\mathrm{Bi}_{2} \mathrm{WO}_{6} \mathrm{Particles}$ suppressed the fast recombination of photoexcited electrons and holes within $1 \mu \mathrm{s}$. In the case of crystallized particles, the density of the photoexcited electron increased with an increase in the crystalline content, and the photocatalytic efficiency for reaction 1 strongly depended on the crystalline content, indicating that photoexcited electrons remaining in the submillisecond time range significantly affect the reaction rate. On the other hand, photocatalytic efficiency for reaction 2 showed a proportional relation with specific surface area rather than crystalline content. The difference in a decisive factor depending on reaction condition is considered to be the slower rate of reaction of photoexcited electrons with molecular oxygen, which might occur within a time range between $200 \mu$ s and 3 ms over $\mathrm{Bi}_{2} \mathrm{WO}_{6}$.
\end{abstract}

\section{INTRODUCTION}

The development of visible light-responsive photocatalysts is needed for effective use of light energy. Semiconductor photocatalytic reactions can be classified into two research fields by consideration of the free energy change $(\Delta G)$ of reactions. ${ }^{1,2}$ Photocatalytic reactions with $\Delta G>0$ are defined as light energy conversion to chemical energy, e.g., water splitting to produce hydrogen. Photocatalytic reaction with $\Delta G<0$, e.g., oxidative decomposition of organic compounds into carbon dioxide $\left(\mathrm{CO}_{2}\right)$, i.e., mineralization, can be considered as energy-saving technology, since the reaction is thermodynamically possible. To achieve photocatalytic water splitting, band edges of the conduction band (CB) and valence band (VB) of a semiconductor photocatalyst must be located at a potential more negative than that for hydrogen evolution ( $0 \mathrm{~V}$ vs standard hydrogen electrode (SHE)) and a potential more positive than that for water oxidation $(+1.23 \mathrm{~V}$ vs $\mathrm{SHE})$, respectively. For mineralization of organic compounds, thermodynamic requirements are expected to be less severe than those for water splitting because $\Delta G<0$. However, in general, the CB edge must be more negative than the potential for one electron reduction of molecular oxygen $\left(\mathrm{O}_{2}\right)$ to produce a superoxide anion $\left(\mathrm{O}_{2}{ }^{\bullet-},-0.28 \mathrm{~V}\right.$ vs $\left.\mathrm{SHE}\right)$ or hydroperoxy radical $\left(\mathrm{HO}_{2} \bullet\right.$, $-0.05 \mathrm{~V}$ vs $\mathrm{SHE})$. This is because the rates of multiple-electron reduction of $\mathrm{O}_{2}$, e.g., production of hydrogen peroxide, are kinetically very slow.

The VB edges of simple metal oxides, which are generally composed of $\mathrm{O} 2 \mathrm{p}$ orbitals, are usually located at around $3.0 \mathrm{~V}$ vs SHE, indicating that it is impossible to develop photocatalysts of simple metal oxides simultaneously exhibiting a narrow band gap $(<3.0 \mathrm{eV})$ and $\mathrm{CB}$ edge more negative than $0 \mathrm{~V}$ vs SHE. ${ }^{3}$ One of the strategies to overcome this problem is surface modification of narrow band gap photocatalysts, e.g., tungsten(VI) oxide with cocatalysts promoting multielectron reduction of $\mathrm{O}_{2}{ }^{4-8}$ Another strategy is creation of an electron donor level near the VB edge of a wide band gap photocatalyst ${ }^{9-15}$ or a new VB composed of orbitals with energy higher than that of the $\mathrm{O} 2 \mathrm{p}$ orbital. ${ }^{16-19}$ Bismuth tungstate $\left(\mathrm{Bi}_{2} \mathrm{WO}_{6}\right)$ is one of the photocatalysts in the latter case. Contribution of the $\mathrm{Bi} 6 \mathrm{~s}$ orbital to the $\mathrm{VB}$ has been reported for $\mathrm{Bi}_{2} \mathrm{WO}_{6}$ crystals based on calculation using a density functional theory. ${ }^{20,21}$ This would provide both a negative $\mathrm{CB}$ edge required for one-electron reduction of $\mathrm{O}_{2}$ and a narrow band gap of $2.6-2.8 \mathrm{eV}$ to absorb the violet part of visible light. Visible light-induced degradation of organic dyes using

Received: $\quad$ May 31, 2011

Revised: July 11, 2011

Published: July 14, 2011 
$\mathrm{Bi}_{2} \mathrm{WO}_{6}$ crystallites has been reported elsewhere, ${ }^{20,22}$ and we have reported relatively high photocatalytic efficiency of $\mathrm{Bi}_{2} \mathrm{WO}_{6}$ flake-ball particles, which are uniform micrometer-sized spherical assemblies of flakes composed of crystalline $\mathrm{Bi}_{2} \mathrm{WO}_{6}$ platelets, for mineralization of acetaldehyde and acetic acid under visible light irradiation. ${ }^{23,24}$ The apparent quantum efficiencies were found to be $3-5 \%$ at $420 \mathrm{~nm}$ irradiation. ${ }^{23,24}$

Time-resolved absorption spectroscopy in the range of femtoseconds to picoseconds has been used to study the process of photoexcited charge carriers in titania photocatalysts: generation, relaxation to trapping sites, recombination of electrons and holes, and charge transfer to reactant molecules. ${ }^{25-29}$ Spectra of three transient species, i.e., surface-trapped holes, surface-trapped electrons, and electrons in bulk, overlap in the visible wavelength region, ${ }^{30}$ but absorption in the infrared (IR) wavelength region is simply assignable to electrons in the $\mathrm{CB} .{ }^{31}$ Recent studies using time-resolved absorption spectroscopy for photocatalysts such as titania, ${ }^{32-35}$ platinized titania, ${ }^{36-38}$ sulfur-doped titania, ${ }^{39,40}$ titania doped with chromium and antimony, ${ }^{40}$ and tantalum oxides $^{41-43}$ have shown that photocatalytic efficiencies for oxygen reduction or water splitting under steady-state irradiation are related to the dynamics of photoexcited electrons in the time range of microseconds to milliseconds rather than ultrafast processes, although transfer of holes to alcohols occurs within $10 \mathrm{~ns}$. For photocatalytic mineralization of organic compounds, it has frequently been reported that the oxygen reduction rate determines the overall reaction rate. ${ }^{44,45}$ However, correlations between the kinetics of photoexcited carriers in the presence of $\mathrm{O}_{2}$ and the photocatalytic efficiency for mineralization have not been studied except for titania-based photocatalysts. ${ }^{32,34,39}$ In addition, there is no information on the effects of crystalline content on photoexcited carrier dynamics and photocatalytic efficiencies. Such information is indispensable to develop visible light-responsive photocatalysts with high efficiency.

In a preliminary work, we have studied the photoexcited electron density in amorphous and crystalline $\mathrm{Bi}_{2} \mathrm{WO}_{6}$ samples using time-resolved IR absorption spectroscopy. ${ }^{23}$ Crystallization of amorphous $\mathrm{Bi}_{2} \mathrm{WO}_{6}$ enhanced the density of photoexcited electrons and the rate of photocatalytic $\mathrm{CO}_{2}$ liberation. ${ }^{23}$ For well-crystallized $\mathrm{Bi}_{2} \mathrm{WO}_{6}$ particles, the rate was increased in proportion to the specific surface area because of the increase in adsorbed amount of acetaldehyde. ${ }^{46}$ However, effects of crystalline content on photoexcited carrier dynamics of $\mathrm{Bi}_{2} \mathrm{WO}_{6}$ photocatalysts have not been elucidated, although the crystalline content is considered to affect the process of recombination and electron transfer to the surface. In this study, we systematically investigated the effect of photoexcited electron density on photocatalytic efficiencies for mineralization of two organic compounds in different conditions, i.e., acetaldehyde in air and acetic acid in an aqueous solution. The effects of crystalline content and specific surface area on photocatalytic efficiencies are also discussed on the basis of our previously reported results ${ }^{46}$ and the dynamics of photoexcited electrons. As far as we know, this is the first report on correlations between crystallization degree, photoexcited electron density, and photocatalytic activity of semiconductor photocatalysts.

\section{EXPERIMENTAL SECTION}

2.1. Preparation of Photocatalysts. $\mathrm{Bi}_{2} \mathrm{WO}_{6}$ particles were prepared by hydrothermal reaction at several temperatures from 373 to $493 \mathrm{~K}^{47,48} \mathrm{~A}$ mixture of bismuth nitrate $(5.0 \mathrm{mmol})$ and an aqueous solution of sodium tungstate $(2.75 \mathrm{mmol})$ was heated in a $100 \mathrm{~mL}$ Teflon-lined autoclave placed in an electric oven for $20 \mathrm{~h}$ under autogenerated pressure. The atomic ratio of tungsten to bismuth (W/Bi ratio) in the feed was adjusted to 0.55 to fabricate flake-ball particles with a well-defined structure. ${ }^{47,48}$ The precipitates obtained by hydrothermal reaction were washed with water and dried at $393 \mathrm{~K}$ in air. The samples were denoted as BW- $x$, in which $x$ means the hydrothermal preparation temperature in units of kelvin.

2.2. Photocatalytic Decomposition of Acetic Acid. A photocatalyst powder $(50 \mathrm{mg})$ was suspended in an aqueous solution $(5.0 \mathrm{~mL})$ containing $5.0 \mathrm{vol} \%$ acetic acid in a glass tube sealed with a rubber septum and irradiated in air under magnetic stirring at $298 \mathrm{~K}$ with a thermostatted water bath. Photoirradiation $(>290 \mathrm{~nm})$ was performed using a $400 \mathrm{~W}$ high-pressure mercury arc lamp (Eiko-sha). Visible light irradiation $(>400 \mathrm{~nm})$ was performed using a $300 \mathrm{~W}$ xenon arc lamp (ILC Technology CERMAX-LX300F) equipped with a cutoff filter (Asahi Techno Glass L42). The amount of liberated $\mathrm{CO}_{2}$ was quantified using a TCD gas chromatograph (Shimadzu GC-8A) equipped with a Porapak-Q column. Effects of electron acceptors on the photocatalytic reaction were investigated using a cylindrical glass vessel connected to a closed gas circulation system with a volume of ca. $300 \mathrm{~mL}$. The photocatalyst powder $(100 \mathrm{mg})$ was suspended in an aqueous solution $(100 \mathrm{~mL})$ containing $5.0 \mathrm{vol} \%$ acetic acid with electron acceptors $\left(5.0 \mathrm{mmol} \mathrm{L}-1\right.$ sodium iodate $\left(\mathrm{NaIO}_{3}\right)$ or $2.5 \mathrm{mmol} \mathrm{L}{ }^{-1}$ silver sulfate $\left.\left(\mathrm{Ag}_{2} \mathrm{SO}_{4}\right)\right)$. After performing evacuation several times to completely remove the air, ca. 400 Torr $(1$ Torr $=133.322 \mathrm{~Pa})$ of argon $(\mathrm{Ar})$ gas was introduced into the vessel. Photoirradiation was performed using a xenon arc lamp equipped with a cold mirror. The gas in the circulation system was analyzed using an online TCD gas chromatograph.

2.3. Photocatalytic Decomposition of Acetaldehyde. Photocatalyst powder $(50 \mathrm{mg})$ spread on a glass plate $(15 \mathrm{~mm} \times$ $15 \mathrm{~mm}$ ) was placed on the bottom of a cylindrical glass vessel with a volume of ca. $330 \mathrm{~mL}$. Gaseous acetaldehyde (2200 ppm, ca. $30 \mu \mathrm{mol}$ ) was injected into the vessel filled with ambient air. After adsorption of acetaldehyde had reached equilibrium in the dark (ca. $30 \mathrm{~min})$, visible light irradiation $(>400 \mathrm{~nm})$ was performed using a xenon arc lamp with a cold mirror and an L42 cutoff filter. The amounts of acetaldehyde and $\mathrm{CO}_{2}$ were measured by a TCD microgas chromatograph (Agilent Technologies 3000A Micro GC) equipped with Plot $\mathrm{U}$ and OV-1 columns.

2.4. Time-Resolved IR Spectroscopy. The photocatalyst powder suspended in ethanol was deposited on a calcium fluoride plate with a density of ca. $1 \mathrm{mg} \mathrm{cm}^{-2}$, followed by drying at room temperature. The thus-obtained film was placed in a stainless-steel cell and evacuated at room temperature for 15 min. Third harmonic light of Q-switched Nd:YAG laser $(355 \mathrm{~nm})$ was used for photoexcitation. The power and duration of the laser pulse were $1 \mathrm{~mJ} \mathrm{~cm}^{-2}$ and $6 \mathrm{~ns}$, respectively. IR light emitted from a molybdenum disilicide source was focused on the film. The transmitted IR light was dispersed in a grating spectrometer and transformed to an electric signal in a photovoltaic mercury cadmium telluride (MCT) detector. The MCT output was amplified in an ac-coupled amplifier and recorded in a digital oscilloscope as a function of delay time. The repetition rates were adjusted to $1.0,2.0$, and $0.25 \mathrm{~Hz}$ for measurement in a vacuum, in the presence of 150 Torr $\mathrm{O}_{2}$, and in the presence of 10 Torr methanol, respectively. The transient absorbance change was recorded by averaging signals of 150-500 flashes. 
2.5. Characterization. X-ray diffraction (XRD) patterns were recorded on a Rigaku RINT ULTIMA diffractometer with $\mathrm{Cu}$ $\mathrm{K} \alpha$ radiation. Raman spectra were recorded on a Perkin-Elmer System 2000R spectrometer with an Nd:YAG laser (1064 nm). The obtained peak intensities were normalized by peak area intensity at $988 \mathrm{~cm}^{-1}$ of barium sulfate as an internal standard. Particle size distributions of aqueous suspensions were measured in the presence of sodium hexametaphosphate as a dispersant by the laser diffraction method using a Shimadzu SALD-7000 particle size analyzer. Specific surface area of the samples evacuated at $393 \mathrm{~K}$ for $2 \mathrm{~h}$ was analyzed by the BrunauerEmmett-Teller theory from nitrogen adsorption isotherms at 77 $\mathrm{K}$ measured using a Yuasa Ionics Autosorb-6-AG surface area analyzer. Scanning transmission electron microscope (STEM) images were observed by a Hitachi HD-2000 with an acceleration voltage of $200 \mathrm{kV}$, and chemical element mapping images on a nanometer scale were obtained by energy dispersive X-ray (EDX) analysis. Images obtained by the scanning electron microscope (SEM) were observed by a JEOL JSM-7400F. UV-vis diffuse reflection spectra were recorded using barium sulfate as a standard material by a JASCO V-670 spectrometer equipped with a PIN757 integrating sphere. Zeta-potential measurements were performed using an Otsuka Electronics ELSZ series analyzer. The $\mathrm{pH}$ of the suspension was adjusted by addition of aqueous solutions of hydrochloric acid and sodium hydroxide.

\section{RESULTS}

3.1. Characterization of $\mathrm{Bi}_{2} \mathrm{WO}_{6}$ Particles. Results of $\mathrm{XRD}$, Raman spectroscopy, SEM observation, EDS analysis, and particle size measurement indicate that BW-373 was randomsized aggregates of amorphous $\mathrm{Bi}_{2} \mathrm{WO}_{6}$ nanoparticles (Figures S1-3 in Supporting Information (SI)). Chemical element mapping images obtained by STEM and EDX analysis suggest that bismuth and tungsten were thoroughly mixed in at least a nanometer order (Figure S4 in SI). BW-383 was also composed of aggregates of amorphous $\mathrm{Bi}_{2} \mathrm{WO}_{6}$ nanoparticles, while it contained a small amount of crystalline flakes. On the other hand, powders prepared at $388 \mathrm{~K}$ or higher were found to be flake-ball particles composed of crystalline $\mathrm{Bi}_{2} \mathrm{WO}_{6}$ platelets. The averaged particle size determined by the laser diffraction method was $4 \mu \mathrm{m}$ (Figure S3 in SI). This particle size was independent of temperature of the hydrothermal preparation for flake-ball particles. The $\mathrm{W} / \mathrm{Bi}$ ratio of flake-ball particles prepared at temperatures $\geq 393 \mathrm{~K}$ was determined by EDX analysis to be ca. 0.58 , which is similar to the ratio in the feed for the hydrothermal reaction, while samples prepared at a low hydrothermal temperature exhibited relatively high $\mathrm{W} / \mathrm{Bi}$ ratios (e.g., 0.62 for BW-383, Table S1 in SI). The wavelength of the photoabsorption edge of BW-393 was longer than that of amorphous BW-373, indicating a red shift of the photoabsorption edge by crystallization (Figure S5 in SI). The band gaps of crystalline flake-ball particles were calculated to be ca. $2.7 \mathrm{eV}$ from diffuse reflectance spectra using a relation assuming an indirect allowed transition. ${ }^{48}$ Figure 1 shows the crystalline contents of samples calculated from XRD patterns using an area intensity of the most intense 131 diffraction peak of $\mathrm{Bi}_{2} \mathrm{WO}_{6}$ crystals, assuming that the area is in proportion to the mass of the crystalline part. Here, BW-493 was used as a standard sample based on the assumption that it is a single-phase crystalline $\mathrm{Bi}_{2} \mathrm{WO}_{6}$. The crystalline content of $\mathrm{BW}-388$ was estimated to be $66 \%$. BW-383 contains a small amount of crystalline $\mathrm{Bi}_{2} \mathrm{WO}_{6}$, but

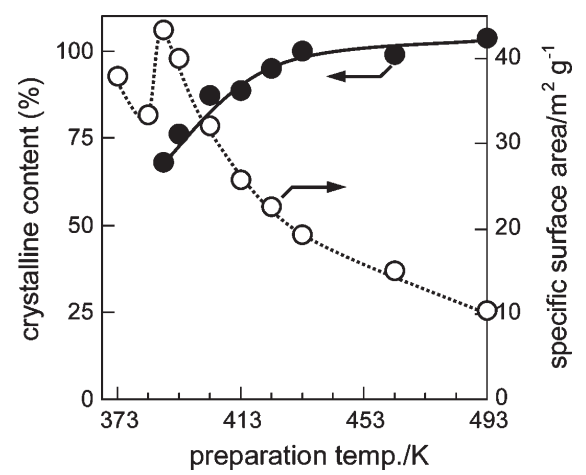

Figure 1. Effects of hydrothermal preparation temperature on ( ) crystalline content and $(O)$ specific surface area of $\mathrm{Bi}_{2} \mathrm{WO}_{6}$ particles. Parts of data were reproduced from ref 46 for comparison and further discussion.
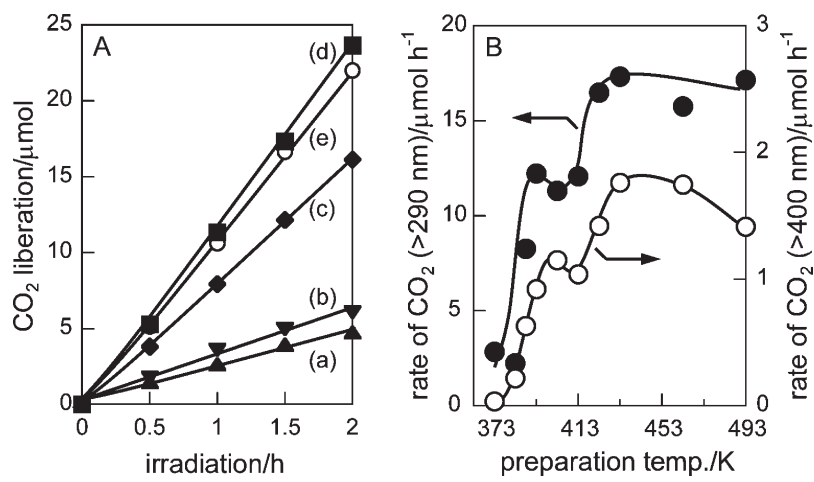

Figure 2. (A) $\mathrm{CO}_{2}$ liberation for reaction 1 under irradiation at wavelengths $>290 \mathrm{~nm}$ over (a) BW-373, (b) 383, (c) 388, (d) 393, and (e) 403. (B) Effect of hydrothermal preparation temperature on the $\mathrm{CO}_{2}$ liberation rate under irradiation at wavelengths $(\bullet)>290 \mathrm{~nm}$ and (O) $>400 \mathrm{~nm}$.

it was difficult to be quantified. The crystalline content shows a tendency to reach $100 \%$ with elevation in preparation temperature. Figure 1 also shows the specific surface areas of samples. The surface area of crystalline $\mathrm{Bi}_{2} \mathrm{WO}_{6}$ particles prepared at 388 $\mathrm{K}$ or higher monotonically decreased with elevation in preparation temperature.

3.2. Photocatalytic Efficiency of $\mathrm{Bi}_{2} \mathrm{WO}_{6}$ Particles. Figure $2 \mathrm{~A}$ shows time courses of photocatalytic decomposition of acetic acid (reaction 1) under irradiation with wavelengths $>290 \mathrm{~nm}$. Monotonic $\mathrm{CO}_{2}$ liberation was observed in the gas phase under steadystate photoirradiation through decomposition of acetic acid expressed as follows: $\mathrm{CH}_{3} \mathrm{COOH}+2 \mathrm{O}_{2} \rightarrow 2 \mathrm{CO}_{2}+2 \mathrm{H}_{2} \mathrm{O}$. ${ }^{49}$ $\mathrm{CO}_{2}$ liberation over BW-373 and BW-383 was much smaller than that over crystallized $\mathrm{Bi}_{2} \mathrm{WO}_{6}$ powders prepared at $388 \mathrm{~K}$ or higher. Figure $2 \mathrm{~B}$ shows the rates of $\mathrm{CO}_{2}$ liberation over $\mathrm{Bi}_{2} \mathrm{WO}_{6}$ samples under irradiation at wavelengths $>290 \mathrm{~nm}$ and $>400 \mathrm{~nm}$ as a function of hydrothermal preparation temperature. Elevation in temperature to $433 \mathrm{~K}$, i.e., increase in the crystalline content and also decrease in the specific surface area, resulted in an increase in photocatalytic reaction rate. Since photoabsorption in the visible-light region was not high, $\mathrm{CO}_{2}$ liberation rate under visible light irradiation $(>400 \mathrm{~nm})$ was only about one-tenth of that under UV-vis light irradiation (>290 nm). However, the dependence of photocatalytic efficiency on preparation temperature was 

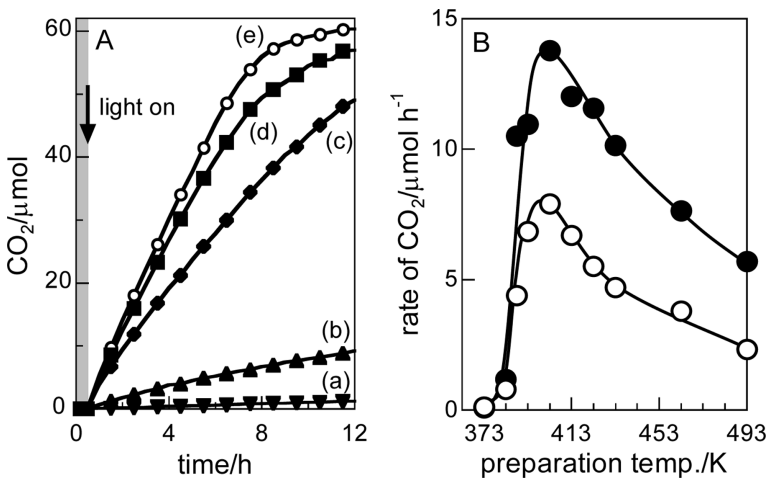

Figure 3. (A) $\mathrm{CO}_{2}$ liberation for reaction 2 under irradiation at wavelengths $>400 \mathrm{~nm}$ over (a) BW-373, (b) 383, (c) 388, (d) 393, and (e) 403. (B) Effect of hydrothermal preparation temperature on the $\mathrm{CO}_{2}$ liberation rate in time range of $(\mathbf{O}) 5-15 \mathrm{~min}$ and $(O) 3-4 \mathrm{~h}$. Parts of data were reproduced from ref 46 for comparison and further discussion.

similar for both irradiation wavelengths, suggesting that the mechanism of photocatalytic reaction for the two wavelengths is the same.

Figure $3 \mathrm{~A}$ shows time courses of $\mathrm{CO}_{2}$ liberation through decomposition of gaseous acetaldehyde in air (reaction 2) under visible light irradiation. The overall reactions could be expressed as follows: $\mathrm{CH}_{3} \mathrm{CHO}+5 / 2 \mathrm{O}_{2} \rightarrow 2 \mathrm{CO}_{2}+2 \mathrm{H}_{2} \mathrm{O}$. The total liberation of $\mathrm{CO}_{2}$ (ca. $\left.60 \mu \mathrm{mol}\right)$ over each sample prepared at $388 \mathrm{~K}$ or higher was two times larger than the amount of acetaldehyde in the feed (ca. $30 \mu \mathrm{mol}$ ) after prolonged irradiation. On the other hand, $\mathrm{CO}_{2}$ liberation was negligible over amorphous BW-373 as previously reported. ${ }^{23}$ For BW-383, $\mathrm{CO}_{2}$ liberation was slow, although acetaldehyde was decreased to some extent during photoirradiation (data not shown). Figure 3B shows the rate of $\mathrm{CO}_{2}$ liberation as a function of hydrothermal preparation temperature. The rates both in time ranges of 5-15 min and 3-4 h were greatly enhanced by crystallization at $383 \mathrm{~K}$. Elevating the temperature higher than $403 \mathrm{~K}$ decreased the $\mathrm{CO}_{2}$ liberation rate because of the gradual decrease in specific surface area as shown in Figure 1. A similar trend was confirmed under irradiation with wavelengths $>290 \mathrm{~nm}^{46}$

3.3. Photodynamics of $\mathrm{Bi}_{2} \mathrm{WO}_{6}$ Particles. Time-resolved IR spectroscopy was performed to evaluate the dynamics of photoexcited carriers in $\mathrm{Bi}_{2} \mathrm{WO}_{6}$ particles. Sensitive detection of photoexcited electrons has been achieved for several types of semiconductor photocatalysts by monitoring the transient structureless IR absorption. ${ }^{31,33,39-43}$ Rapid buildups of IR absorption were observed for $\mathrm{Bi}_{2} \mathrm{WO}_{6}$ particles prepared at $383 \mathrm{~K}$ or higher after $355 \mathrm{~nm}$ pulse excitation in vacuum. This decay in the absence of electron acceptors and donors is attributable to the generation of photoexcited electrons and recombination with positive holes. Since the decay of structureless transient IR absorption was independent of the IR wavenumber in the range of $1700-3700 \mathrm{~cm}^{-1}$ for BW-403, absorbance intensity at $2000 \mathrm{~cm}^{-1}$ was selected for measurement of time decays. Figure 4A shows the decay profiles observed on a time scale of $0-100 \mu$ s after pulse excitation for $\mathrm{Bi}_{2} \mathrm{WO}_{6}$ samples prepared at various temperatures. No transient IR absorption was observed for a fully amorphous sample, i.e., BW-373, indicating fast recombination of photoexcited carriers within $1 \mu \mathrm{s} .{ }^{23} \mathrm{BW}-383$ exhibited a small change in IR absorbance, suggesting enhancement of photoexcited electron lifetime probably due to the presence of a small amount of crystallized $\mathrm{Bi}_{2} \mathrm{WO}_{6}$. However, the
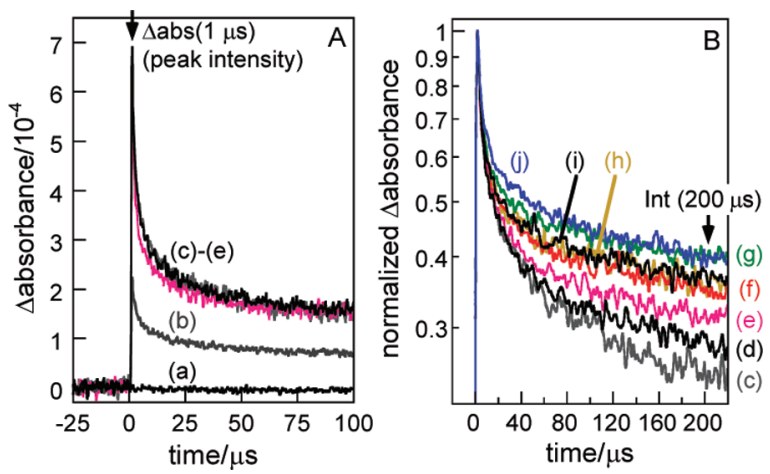

Figure 4. (A) Time decay profiles of absorbance change at $2000 \mathrm{~cm}^{-1}$ observed on $\mathrm{Bi}_{2} \mathrm{WO}_{6}$ particles after $355 \mathrm{~nm}$ pulse excitation in vacuum and (B) the profiles normalized by intensity at $1 \mu$ s delay: (a) BW-373, (b) 383, (c) 388, (d) 393, (e) 403, (f) 413, (g) 423, (h) 433, (i) 463, and (j) 493.
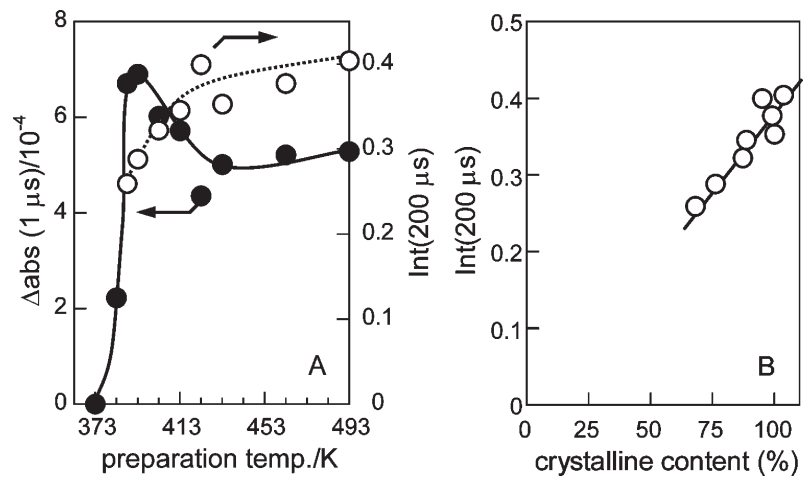

Figure 5. (A) Effect of hydrothermal preparation temperature on ( ) the peak intensity of IR absorbance change at ca. $1 \mu$ s delay $(\Delta \mathrm{abs}(1 \mu \mathrm{s}))$ and $(O)$ the intensity of normalized absorbance change at $200 \mu$ s delay $(\operatorname{Int}(200 \mu \mathrm{s}))$. (B) Plots of $\operatorname{Int}(200 \mu \mathrm{s})$ as a function of crystalline content of $\mathrm{Bi}_{2} \mathrm{WO}_{6}$ particles.

intensity of IR absorption was smaller than that for well-crystallized samples since BW-383 contains a large amount of amorphous parts working as recombination centers.

Figure 5A shows the peak intensity of IR absorbance change after pulse excitation $(\Delta \mathrm{abs}(1 \mu \mathrm{s}))$ as a function of preparation temperature of $\mathrm{Bi}_{2} \mathrm{WO}_{6}$ powders. The peak intensity is related to the density of photoexcited electrons escaping from fast recombination. The $\Delta \mathrm{abs}(1 \mu \mathrm{s})$ was greatly enhanced by elevation in preparation temperature but then decreased to a plateau at a high temperature. This indicates that crystallization is essential to escape from the fast recombination and that the degree of crystallization is not the sole factor for determining the density of photoexcited electrons surviving longer than $1 \mu \mathrm{s}$. The specific surface area of BW-388 was largest among the samples, and it gradually decreased with elevation of preparation temperature. Femtosecond transient absorption spectroscopy of titania under a weak excitation condition revealed that electrons and holes survive for several microseconds after spatial charge separation of holes at the surface and electrons in the bulk within a 500 ps time constant. $^{28}$ Therefore, a larger surface area might be efficient to trap holes, resulting in more efficient charge separation. High specific surface area or, in other words, small crystalline size is also beneficial to decrease the pass length of photoexcited carriers 

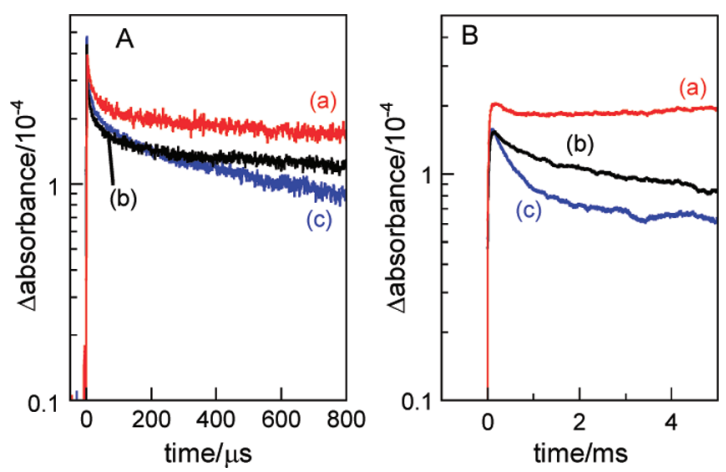

Figure 6. Time decay profiles of absorbance change at $2000 \mathrm{~cm}^{-1}$ observed on BW-433 after $355 \mathrm{~nm}$ pulse excitation in (a) the presence of 10 Torr of methanol, (b) vacuum, and (c) the presence of 100 Torr of $\mathrm{O}_{2}$. Profiles (A) and (B) show the decay observed on a time range of $0-800 \mu \mathrm{s}$ and $0-5 \mathrm{~ms}$, respectively.

from the bulk to the surface. Since fast recombination within $1 \mu \mathrm{s}$ would depend on both the degree of crystallization and crystalline size, it seems impossible to correlate the recombination dynamics with only one physical property.

Figure $4 \mathrm{~B}$ shows IR absorbance change normalized by $\Delta \mathrm{abs}(1 \mu \mathrm{s})$. When recombination time was evaluated as the time required for $50 \%$ of the initial intensity, the difference in recombination times $(15-50 \mu \mathrm{s})$ was relatively small. On the other hand, the decays of normalized intensity in the submillisecond range were quite different among the samples. Decay due to recombination was decelerated by an elevation in preparation temperature. Open circles in Figure 5A show plots of the intensity at $200 \mu$ s for normalized absorbance change $(\operatorname{Int}(200 \mu \mathrm{s}))$. $\operatorname{Int}(200 \mu \mathrm{s})$ increased to saturation with temperature elevation. Figure $5 \mathrm{~B}$ shows the relation between crystalline content and $\operatorname{Int}(200 \mu \mathrm{s})$. Int $(200 \mu \mathrm{s})$ monotonously increased with an increase in crystalline content, indicating that the density of photoexcited electrons remaining in the submillisecond range was enhanced by an increase in crystalline content. This would be because of the decrease in amorphous parts and crystalline defects, which are recognized to act as recombination centers.

Figure 6 shows the decay profiles of absorbance change at $2000 \mathrm{~cm}^{-1}$ for BW-433 in the presence of gaseous methanol or $\mathrm{O}_{2}$. The intensity was greatly enhanced by the presence of methanol as a hole scavenger, indicating that the mid-IR absorbance change is attributed to photoexcited electrons but not to holes. Since surface-trapped holes of titania react with alcohols within the nanosecond range $(0.3 \mathrm{~ns}$ and $1 \mathrm{~ns}$ time constant for methanol and ethanol), ${ }^{27}$ recombination between photoexcited electrons with holes is suppressed in the millisecond range ( $\sim 550 \mathrm{~ms}$ halftime $).{ }^{32,38}$ For BW-433, the rate of hole transfer to methanol was found to be within $100 \mu$ s by comparison with the time decays in a vacuum and in the presence of methanol. In the presence of $\mathrm{O}_{2}$, decay at time delays of $0-3 \mathrm{~ms}$ was accelerated by the consumption of photoexcited electrons by $\mathrm{O}_{2}$, while the decay profile was similar to that in a vacuum at time delays of $0-200 \mu \mathrm{s}$. This indicates that electron transfer to $\mathrm{O}_{2}$ is a slow reaction in the time range of a few milliseconds and negligible within $200 \mu$ s. It has been reported that the rate of $\mathrm{O}_{2}$ reduction by the photoexcited electrons in titania particles is also slow (Gerischer and Heller mentioned that experimental data indicate much slower electron-transfer rate from semiconductors to oxygen than theoretical analysis predicts, ca. $330 \mu \mathrm{s}) .^{32,44}$

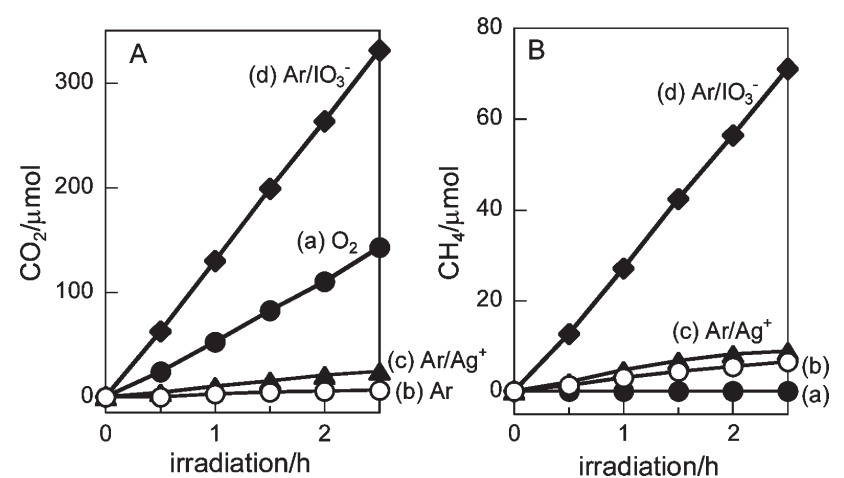

Figure 7. Effect of electron acceptors on (A) $\mathrm{CO}_{2}$ and (B) $\mathrm{CH}_{4}$ liberation through decomposition of acetic acid in an aqueous solution under irradiation at wavelengths $>290 \mathrm{~nm}$ The reactions were performed under (a) $\mathrm{O}_{2}$, (b) $\mathrm{Ar}$, (c) Ar in the presence of $\mathrm{Ag}_{2} \mathrm{SO}_{4}$, and (d) $\mathrm{Ar}$ in the presence of $\mathrm{NaIO}_{3}$. The dosages of silver cation and iodate anion in an aqueous solution were adjusted to $500 \mu \mathrm{mol}$.

Some photoexcited electrons remained in the millisecond range without reaction with $\mathrm{O}_{2}$ and recombination, but they were completely consumed within $500 \mathrm{~ms}$ since the measurement in the presence of $\mathrm{O}_{2}$ could be performed at a repetition rate of $2 \mathrm{~Hz}$.

3.4. Effect of Electron Acceptors in Photocatalytic Reaction. Figure 7 shows $\mathrm{CO}_{2}$ and methane $\left(\mathrm{CH}_{4}\right)$ liberation through decomposition of acetic acid in an aqueous solution with and without an electron acceptor. Silver cation and iodate anion play a role in electron capture as follows: $\mathrm{Ag}^{+}+\mathrm{e}^{-} \rightarrow \mathrm{Ag}$ and $\mathrm{IO}_{3}{ }^{-}+6 \mathrm{H}^{+}$ $+6 \mathrm{e}^{-} \rightarrow \mathrm{I}^{-}+3 \mathrm{H}_{2} \mathrm{O}$. The rate of photocatalytic $\mathrm{CO}_{2}$ liberation was enhanced by substitution of dissolved $\mathrm{O}_{2}$ with iodate anion ${ }^{50}$ but was decreased by the addition of a silver cation instead of dissolved $\mathrm{O}_{2}$, suggesting that the reactivity of photoexcited electrons with electron acceptors significantly affects the rate of decomposition of organic compounds. Photocatalytic reaction under Ar without electron acceptors induced liberation of a small amount of $\mathrm{CH}_{4}$, while $\mathrm{CO}_{2}$ liberation was negligible. In the presence of iodate anions, a considerable amount of $\mathrm{CH}_{4}$ was monotonically liberated with irradiation. $\mathrm{CH}_{4}$ would be produced from the reaction between electron, proton, and methyl radical $\left(\mathrm{CH}_{3} \bullet\right)$, which is intermediately formed by one-electron oxidation of acetic acid accompanying the liberation of one molecule of $\mathrm{CO}_{2}{ }^{51} \mathrm{In}$ the case of photocatalytic decarboxylation of acetic acid (Photo-Kolbe reaction) using platinized titania powder, the amount of $\mathrm{CH}_{4}$ liberation should be the same as the amount of $\mathrm{CO}_{2}$ liberation $\left(\mathrm{CH}_{3} \mathrm{COOH} \rightarrow \mathrm{CH}_{4}+\mathrm{CO}_{2}\right) .{ }^{51}$ However, in this case, the amount of $\mathrm{CH}_{4}$ was smaller than the amount of $\mathrm{CO}_{2}$ probably due to the presence of the iodate anion, which is a strong electron acceptor. The reaction stoichiometry is not confirmed since we have not determined the concentration of $\mathrm{IO}_{3}{ }^{-}$reduced after the reaction. On the other hand, $\mathrm{CH}_{4}$ liberation was negligible in the presence of $\mathrm{O}_{2}$ as a sole electron acceptor. If the concentration of $\mathrm{O}_{2}$ is relatively high, $\mathrm{CH}_{3} \cdot$ rapidly reacts with $\mathrm{O}_{2}$, resulting in further oxidative decomposition into $\mathrm{CO}_{2}$. These results indicate that photocatalytic efficiency and product selectivity are significantly influenced by the type of electron acceptor. The difference in photocatalytic efficiencies is expected to be due to a kinetic reason rather than a thermodynamic reason since the difference between the redox potentials for $\mathrm{Ag}^{+} / \mathrm{Ag}$ and $\mathrm{IO}_{3}{ }^{-} / \mathrm{I}^{-}$, which are +0.80 and $+0.91 \mathrm{~V}$ vs SHE, at $\mathrm{pH}=3$ is not so large. The isoelectric point of BW-433 was found to be $\mathrm{pH}$ of ca. 7 by measurement of zeta 

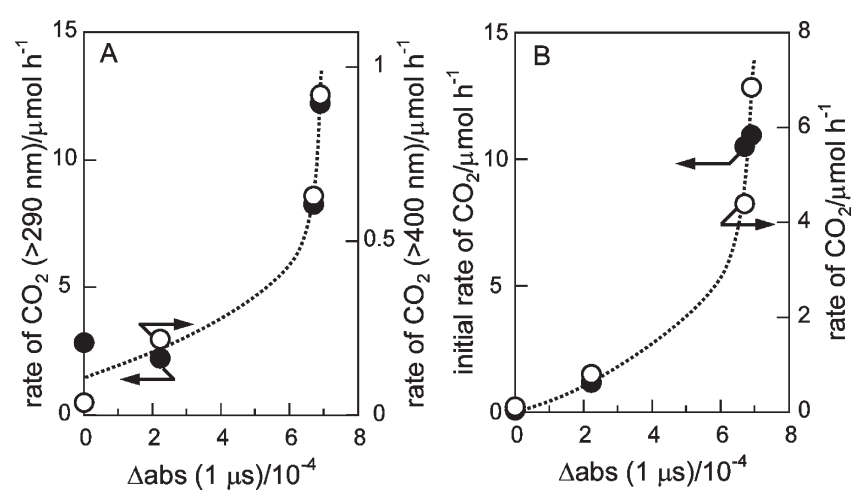

Figure 8. Effects of $\Delta \mathrm{abs}(1 \mu \mathrm{s})$ on the rates of photocatalytic $\mathrm{CO}_{2}$ liberation as for (A) reaction 1 under irradiation at wavelengths $(\mathbf{O})$ $>290 \mathrm{~nm}$ and $(\mathrm{O})>400 \mathrm{~nm}$, and $(\mathrm{B})$ reaction 2 on a time scale of $(\bullet)$ 5-15 min and $(\mathrm{O}) 3-4 \mathrm{~h}$. The data of $\mathrm{Bi}_{2} \mathrm{WO}_{6}$ particles prepared at 373-393 K were plotted.

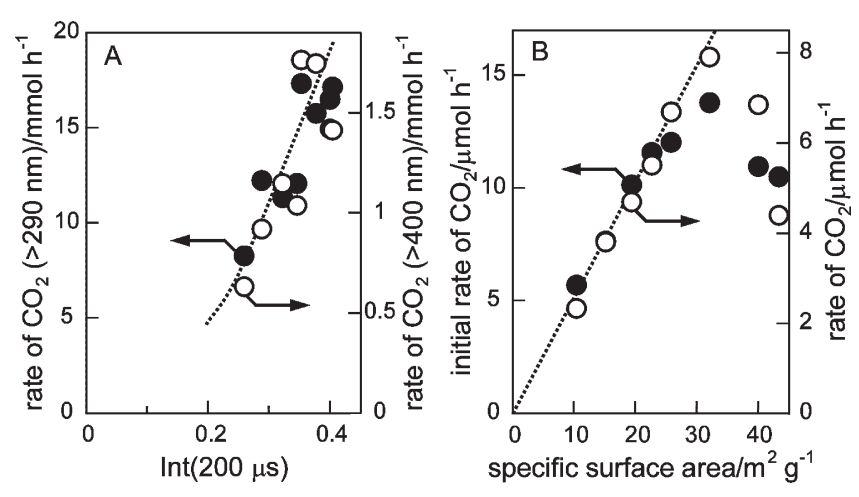

Figure 9. Rates of photocatalytic $\mathrm{CO}_{2}$ liberation for (A) reaction 1 and (B) reaction 2 as a function of $\operatorname{Int}(200 \mu \mathrm{s})$ and specific surface area, respectively. Symbols are the same as those in Figure 8. The data of $\mathrm{Bi}_{2} \mathrm{WO}_{6}$ particles prepared at $383-493 \mathrm{~K}$ were plotted.

potentials (Figure S6 in SI). Since the $\mathrm{pH}$ of aqueous solution of $5 \mathrm{vol} \%$ acetic acid was ca. 3 , the surface of crystalline $\mathrm{Bi}_{2} \mathrm{WO}_{6}$ was positively charged in the solution. Therefore, iodate anions would be easily adsorbed on the photocatalyst surface, resulting in enhancement of the reaction rate of photoexcited electrons with anions. On the other hand, it would be difficult for a silver cation to be adsorbed on the positively charged surface due to electrostatic repulsion. This would be the reason for the slow photocatalytic reaction when the silver cation was used as an electron acceptor.

\section{DISCUSSION}

Figure 8 shows $\mathrm{CO}_{2}$ liberation rates in reaction 1 and reaction 2 as a function of $\Delta \mathrm{abs}(1 \mu \mathrm{s})$. When $\Delta \mathrm{abs}(1 \mu \mathrm{s})$ was small, $\mathrm{CO}_{2}$ liberation was slow in both reactions with different wavelength ranges of irradiation. These results indicate that the density of photoexcited electrons surviving longer than $1 \mu$ s is essential to induce photocatalytic mineralization of organic compounds. The negligible photocatalytic efficiency of amorphous particles was attributed to the fast recombination within $1 \mu \mathrm{s} .{ }^{23}$ For reaction 1 , photocatalytic efficiency of $\mathrm{Bi}_{2} \mathrm{WO}_{6}$ particles increased with elevation of preparation temperature to ca. $423 \mathrm{~K}$ and then reached a plateau. On the other hand, photocatalytic efficiency for reaction 2 was maximized on $\mathrm{Bi}_{2} \mathrm{WO}_{6}$ particles prepared at $403 \mathrm{~K}$ and gradually decreased with elevation of preparation temperature, accompanied by a decrease in specific surface area. Figure $9 \mathrm{~A}$ shows $\mathrm{CO}_{2}$ liberation rate for reaction 1 plotted against Int $(200 \mu \mathrm{s})$. The liberation rate monotonically increased with an increase in $\operatorname{Int}(200 \mu \mathrm{s})$, indicating that a slow reaction process in a few hundreds of microseconds affects the rate of overall photocatalytic reaction for reaction 1 . Increase in the liberation rate with increase in $\operatorname{Int}(200 \mu \mathrm{s})$ suggests that the photocatalytic efficiency is related to crystalline content rather than specific surface area since there is a proportional relation between crystalline content and Int $(200 \mu \mathrm{s})$ (Figure 5B). In the case of reaction 2 , the photocatalytic efficiencies in both the ranges of 5-15 min and of 3-4 h were almost proportional to specific surface area when the specific surface area was less than $25 \mathrm{~m}^{2} \mathrm{~g}^{-1}$ (Figure 9B). As previously reported, the initial rate of acetaldehyde degradation was expressed by first-order kinetics with respect to the amount of surface-adsorbed acetaldehyde when $\mathrm{Bi}_{2} \mathrm{WO}_{6}$ flake-ball particles exhibited similar levels of crystalline content, and the capacity for reactant adsorption was proportional to the specific surface area. ${ }^{46}$ The present study revealed that samples with specific surface area less than $25 \mathrm{~m}^{2} \mathrm{~g}^{-1}$, which were prepared at 403-493 $\mathrm{K}$, exhibited values similar to those of $\operatorname{Int}(200 \mu$ s $)$, i.e., similar rate of electrohole recombination in the submillisecond range. This indicates that photocatalytic efficiency for reaction 2 is proportionally related to specific surface area when photoexcited carrier lifetimes are similar in the time range of submilliseconds. On the other hand, the photocatalytic efficiencies deviated from linearity when specific surface area was large as shown in Figure 9B. This is probably due to fast recombination in the submillisecond range owing to less crystallinity.

The photocatalytic decomposition of gaseous acetic acid in air was tested by substituting acetaldehyde (Figure S7 in SI). The rate of $\mathrm{CO}_{2}$ liberation over BW-403 with a large surface area was higher than that over BW-433 for decomposition of gaseous acetic acid, similar to the results for decomposition of gaseous acetaldehyde in air (Figure 2B). These results suggest that photocatalytic efficiency for mineralization of organic compounds depends on the reaction conditions rather than difference in reactant molecules, e.g., acetic acid and acetaldehyde. In the case of a gas-solid system, there is a sufficient amount of $\mathrm{O}_{2}$ near the photocatalyst surface. On the other hand, the solubility of $\mathrm{O}_{2}$ in water is not so high, e.g., $1.3 \mu \mathrm{mol}$ of $\mathrm{O}_{2}(101.325 \mathrm{kPa})$ in $1 \mathrm{~g}$ of water at $25{ }^{\circ} \mathrm{C}$, suggesting that the chance for photoexcited electrons to react with $\mathrm{O}_{2}$ is limited in the case of a liquid-solid system. Actually, addition of an electron acceptor strongly affected the photocatalytic efficiency in an aqueous solution as shown in Figure 7. In addition, the rate of electron transfer to $\mathrm{O}_{2}$, which occurs after a $200 \mu$ s delay, was much lower than the rate of hole transfer to methanol. These results clearly show that kinetics of $\mathrm{O}_{2}$ reduction plays critical roles in determining the efficiency for a liquid-solid reaction system. Therefore, a greater amount of photoexcited electrons surviving longer than $200 \mu \mathrm{s}$ is thought to be a decisive factor of $\mathrm{Bi}_{2} \mathrm{WO}_{6}$ photocatalysts for mineralization of organic compounds in an aqueous solution.

\section{CONCLUSION}

We investigated correlations between degree of crystallization, density of photoexcited electron, and photocatalytic activity of a 
$\mathrm{Bi}_{2} \mathrm{WO}_{6}$ visible light-sensitive photocatalyst. Gradual increase in crystalline content increased the number of photoexcited electrons remaining in the submillisecond range and enhanced the photocatalytic efficiency of $\mathrm{Bi}_{2} \mathrm{WO}_{6}$ crystallites for mineralization of organic compounds. Electron transfer to $\mathrm{O}_{2}$ over the $\mathrm{Bi}_{2} \mathrm{WO}_{6}$ surface occurred in the time range of $200 \mu \mathrm{s}$ to a few milliseconds, and easily adsorbed electron acceptors significantly enhanced the rate of $\mathrm{CO}_{2}$ liberation compared to that in the case of $\mathrm{O}_{2}$ as a sole electron acceptor, suggesting that the density of photoexcited electrons remaining in the submillisecond range was a decisive factor of photocatalytic efficiency for reaction 1 (liquid-solid reaction system), i.e., mineralization of organic compounds in the condition with a low concentration of $\mathrm{O}_{2}$. On the other hand, the photocatalytic efficiency for reaction 2 (gas-solid reaction system) was dependent on specific surface area of crystalline $\mathrm{Bi}_{2} \mathrm{WO}_{6}$ photocatalysts. It should be emphasized that the photocatalytic efficiency for oxidative decomposition of organic compounds is related to the concentration of $\mathrm{O}_{2}$. These findings based on photoexcited carrier dynamics indicate the importance of designing visible light-responsive photocatalysts to enhance the efficiency.

\section{ASSOCIATED CONTENT}

S Supporting Information. XRD patterns, Raman spectra, SEM and STEM images, particle size distributions, UVvis diffuse reflection spectra, and zeta potentials. This material is available free of charge via the Internet at http://pubs. acs.org.

\section{AUTHOR INFORMATION}

\section{Corresponding Author}

*E-mail: amano@cat.hokudai.ac.jp.

\section{ACKNOWLEDGMENT}

This work was supported by a Grant-in-Aid for Young Scientists (B) (No. 21750202) from the Ministry of Education, Culture, Sports, Science and Technology (MEXT) and a Grant-in-Aid for Challenging Exploratory Research (No. 23655187) from the Japan Society for the Promotion of Science (JSPS).

\section{REFERENCES}

(1) Bard, A. J. Science 1980, 207, 139.

(2) Kudo, A.; Kato, H.; Tsuji, I. Chem. Lett. 2004, 33, 1534.

(3) Scaife, D. E. Sol. Energy 1980, 25, 41.

(4) Abe, R.; Takami, H.; Murakami, N.; Ohtani, B. J. Am. Chem. Soc. 2008, 130, 7780 .

(5) Arai, T.; Horiguchi, M.; Yanagida, M.; Gunji, T.; Sugihara, H.; Sayama, K. J. Phys. Chem. C 2009, 113, 6602.

(6) Irie, H.; Miura, S.; Kamiya, K.; Hashimoto, K. Chem. Phys. Lett. 2008, 457, 202.

(7) Kim, Y. H.; Irie, H.; Hashimoto, K. Appl. Phys. Lett. 2008, 92, 182107.

(8) Arai, T.; Yanagida, M.; Konishi, Y.; Iwasaki, Y.; Sugihara, H.; Sayama, K. Catal. Commun. 2008, 9, 1254.

(9) Matsumura, M.; Hiramoto, M.; Tsubomura, H. J. Electrochem. Soc. 1983, 130, 326.

(10) Konta, R.; Ishii, T.; Kato, H.; Kudo, A. J. Phys. Chem. B 2004, $108,8992$.
(11) Asahi, R.; Morikawa, T.; Ohwaki, T.; Aoki, K.; Taga, Y. Science 2001, 293, 269.

(12) Kato, H.; Kudo, A. J. Phys. Chem. B 2002, 106, 5029.

(13) Irie, H.; Watanabe, Y.; Hashimoto, K. J. Phys. Chem. B 2003, 107,5483 .

(14) Nakamura, R.; Tanaka, T.; Nakato, Y. J. Phys. Chem. B 2004, $108,10617$.

(15) Tachikawa, T.; Takai, Y.; Tojo, S.; Fujitsuka, M.; Irie, H.; Hashimoto, K.; Majima, T. J. Phys. Chem. B 2006, 110, 13158.

(16) Yoshimura, J.; Ebina, Y.; Kondo, J.; Domen, K.; Tanaka, A. J. Phys. Chem. 1993, 97, 1970.

(17) Kato, H.; Kobayashi, H.; Kudo, A. J. Phys. Chem. B 2002, $106,12441$.

(18) Hosogi, Y.; Shimodaira, Y.; Kato, H.; Kobayashi, H.; Kudo, A. Chem. Mater. 2008, 20, 1299.

(19) Maeda, K.; Domen, K. J. Phys. Chem. C 2007, 111, 7851.

(20) Fu, H. B.; Pan, C. S.; Yao, W. Q.; Zhu, Y. F. J. Phys. Chem. B 2005, 109, 22432.

(21) Shimodaira, Y.; Kato, H.; Kobayashi, H.; Kudo, A. J. Phys. Chem. B 2006, 110, 17790.

(22) Fu, H. B.; Zhang, L. W.; Yao, W. Q.; Zhu, Y. F. Appl. Catal., B 2006, 66, 100.

(23) Amano, F.; Yamakata, A.; Nogami, K.; Osawa, M.; Ohtani, B. J. Am. Chem. Soc. 2008, 130, 17650.

(24) Amano, F.; Nogami, K.; Ohtani, B. J. Phys. Chem. C 2009, $113,1536$.

(25) Rothenberger, G.; Moser, J.; Gratzel, M.; Serpone, N.; Sharma, D. K. J. Am. Chem. Soc. 1985, 107, 8054.

(26) Ohtani, B.; Bowman, R. M.; Colombo, D. P.; Kominami, H.; Noguchi, H.; Uosaki, K. Chem. Lett. 1998, 579.

(27) Tamaki, Y.; Furube, A.; Murai, M.; Hara, K.; Katoh, R.; Tachiya, M. J. Am. Chem. Soc. 2006, 128, 416.

(28) Tamaki, Y.; Furube, A.; Murai, M.; Hara, K.; Katoh, R.; Tachiya, M. Phys. Chem. Chem. Phys. 2007, 9, 1453.

(29) Tamaki, Y.; Hara, K.; Katoh, R.; Tachiya, M.; Furube, A. J. Phys. Chem. C 2009, 113, 11741.

(30) Yoshihara, T.; Katoh, R.; Furube, A.; Tamaki, Y.; Murai, M.; Hara, K.; Murata, S.; Arakawa, H.; Tachiya, M. J. Phys. Chem. B 2004, 108, 3817.

(31) Yamakata, A.; Ishibashi, T.; Onishi, H. J.Mol. Catal. 2003, 199, 85.

(32) Peiro, A. M.; Colombo, C.; Doyle, G.; Nelson, J.; Mills, A.; Durrant, J. R. J. Phys. Chem. B 2006, 110, 23255.

(33) Yamakata, A.; Ishibashi, T.; Onishi, H. Chem. Phys. 2007, 339, 133.

(34) Tachikawa, T.; Fujitsuka, M.; Majima, T. J. Phys. Chem. C 2007, $111,5259$.

(35) Tang, J. W.; Durrant, J. R.; Klug, D. R. J. Am. Chem. Soc. 2008, 130, 13885 .

(36) Yamakata, A.; Ishibashi, T.; Onishi, H. Chem. Phys. Lett. 2001, 333, 271.

(37) Yamakata, A.; Ishibashi, T.; Onishi, H. J. Phys. Chem. B 2001, 105,7258 .

(38) Yamakata, A.; Ishibashi, T.; Onishi, H. J. Phys. Chem. B 2002, 106, 9122.

(39) Takeshita, K.; Yamashita, A.; Ishibashi, T.; Onishi, H.; Nishijima, K.; Ohno, T. J. Photochem. Photobiol. A 2006, 177, 269.

(40) Ikeda, T.; Nomoto, T.; Eda, K.; Mizutani, Y.; Kato, H.; Kudo, A.; Onishi, H. J. Phys. Chem. C 2008, 112, 1167.

(41) Yamakata, A.; Ishibashi, T.; Kato, H.; Kudo, A.; Onishi, H. J. Phys. Chem. B 2003, 107, 14383.

(42) Ikeda, T.; Fujiyoshi, S.; Kato, H.; Kudo, A.; Onishi, H. J. Phys. Chem. B 2006, 110, 7883.

(43) Maruyama, M.; Iwase, A.; Kato, H.; Kudo, A.; Onishi, H. J. Phys. Chem. C 2009, 113, 13918.

(44) Gerischer, H.; Heller, A. J. Phys. Chem. 1991, 95, 5261.

(45) Wang, C. M.; Heller, A.; Gerischer, H. J. Am. Chem. Soc. 1992, 114,5230 .

(46) Amano, F.; Nogami, K.; Tanaka, M.; Ohtani, B. Langmuir 2010, $26,7174$. 
(47) Amano, F.; Nogami, K.; Abe, R.; Ohtani, B. Chem. Lett. 2007, 36, 1314.

(48) Amano, F.; Nogami, K.; Abe, R.; Ohtani, B. J. Phys. Chem. C 2008, 112,9320 .

(49) Kominami, H.; Kato, J. I.; Kohno, M.; Kera, Y.; Ohtani, B. Chem. Lett. 1996, 25, 1051.

(50) Ohtani, B.; Nohara, Y.; Abe, R. Electrochemistry 2008, 76, 147.

(51) Kraeutler, B.; Bard, A. J. J. Am. Chem. Soc. 1978, 100, 2239-2240. 